\title{
Apontamentos acerca da integração entre conteúdos de design e de moda no percurso de implementação do design de moda
}

\author{
Notes about the content integration between design and fashion in the course of \\ implementation of the fashion design
}

\author{
Silva, Barbará Cravo da; Mestranda; \\ Universidade de São Paulo - USP \\ babicravo@gmail.com
}
Nascimento, Luis Cláudio Portugal; Doutor;
Universidade de São Paulo - USP
claudioportugal@usp.br

\begin{abstract}
RESUMO
A presente comunicação tem como objetivo investigar o recente percurso histórico do design de moda. Para tanto, adota-se a revisão de literatura como instrumento de análise e contextualização histórica deste percurso e dos elementos que possibilitaram seu surgimento. Tendo em vista que este cenário encontra-se ainda em formatação, pretende-se analisar o contexto atual de implementação do design de moda no âmbito acadêmico, assim como as transformações em seu ambiente de atuação.
\end{abstract}

Palavras Chave: design de moda; contextualização histórica; integração de conteúdos.

\begin{abstract}
This Communication aims to investigate the recent historical background of fashion design. The literature review is adopted as a tool for analysis and historical contextualization of this course and the elements that allowed their demand and implementation. Given that this scenario is still formatting, we will analyze the current context of implementation of the fashion design in the academic as well as changes in your work environment.
\end{abstract}

Keywords: fashion design; historical context; content integration.

\section{$O$ design de moda no Brasil}

A atual aproximação entre design e moda no Brasil se deu primeiramente no âmbito acadêmico, o que não exclui a participação do setor produtivo junto às articulações acadêmicas. Segundo Pires (2007), o design de moda tem sua origem a partir da demanda manifestada pelo próprio setor produtivo em vista da exigência de aprimoramento profissional para enfrentar os desafios gerados pelo novo contexto social, dentre os quais a autora enfatiza a crescente cultura do corpo e da aparência, o surgimento de novos nichos de mercado e a manifestação de novos comportamentos por parte dos consumidores.

Percurso semelhante pode ser notado no momento de mobilização e estruturação do primeiro curso de ensino superior em moda no Brasil, no final da década de 1980. A evolução da moda na academia teve início na disciplina "Desenho de Moda" ministrada nos cursos de Bacharelado e Licenciatura em Desenho e Plástica da Faculdade Santa Marcelina, abrindo caminho para o que posteriormente viria a se tornar o primeiro curso de ensino superior em Desenho de Moda, em 1987, na cidade de São Paulo 
Apontamentos acerca da integração entre conteúdos de design e de moda no percurso ... design de moda

(PIRES, 2002). Fundamentam a construção e consolidação deste percurso acadêmico, iniciativas como a do primeiro curso de longa duração em nível técnico ofertado no Rio de Janeiro pelo SENAI-CETIQT, em 1984, e a do curso de extensão em Estilismo e Modelagem do Vestuário na Universidade Federal de Minas Gerais, em 1986.

A trajetória acadêmica da moda é tardia em comparação a outros campos, o que gerou um contingente de profissionais autodidatas, assim como o entendimento de que "a atividade podia ser exercida por qualquer pessoa com certo talento artístico, informação de moda e "bom gosto'" (Pires, 2007 , p. 4), sendo possível detectar o reflexo deste pressuposto ainda hoje, no momento em que modelos e celebridades assumem o posto de co-criadores e desenvolvem coleções para empresas.

O surgimento dos primeiros cursos de moda no país, sendo eles em nível técnico ou superior, foi impulsionado pela conjuntura vigente, devido "ao aquecimento da economia daquele período, à instalação de novas indústrias de fiação, de têxteis e de confecção de vestuário, da posterior política de abertura de mercado" (PIRES, 2002, p.2). O objetivo maior era libertar a moda do amadorismo, "a partir de então, as fábricas assumiram a produção material dos vestuários e a teoria passou para o domínio da Universidade" (PIRES, 2002, p. 9), o que passou a exigir do setor maior capacitação profissional, como evidenciado por Sousa; Neira e Bastian (2010):

\footnotetext{
"Tornou-se necessário o desenvolvimento de competências correlatas ao que poderia ser chamado desenvolvimento do 'gênio', 'dom' ou 'talento' inato. Assim, a escola ou a 'formação oficial' em moda assume um lugar de destaque para o desenvolvimento profissional, tornando-se praticamente obrigatória." (SOUSA; NEIRA; BASTIAN, 2010, p.6)
}

Segundo Pires (2002), na década de 1970, a diretora do Studio Berçot de Paris, Marie Rucki, era presença constante no Brasil para ministrar cursos livres de estilismo, como alternativa à lacuna do ensino formal, influenciando importantes profissionais brasileiros, como Jun Nakao, Reinaldo Lourenço, André Lima e Ocimar Versolato. Marie Rucki mantém contato com o país ministrando cursos e palestras até os dias de hoje, e tem a opinião de que "o Brasil crescerá como potência de moda quando assumir sua própria identidade e oferecer, aliado a ela, o padrão de qualidade exigido pelo mercado internacional" (Pires, 2002, p. 6).

Neste sentido, a última década foi muito positiva para a moda brasileira ao se tratar da visibilidade que vem conquistando no exterior. Corroborando tal fato, recentemente a renomada empresa do segmento underwear feminino, Victoria's Secret, lançou uma coleção de moda praia com o tema "From Brazil with love", inspirada nas praias brasileiras". No entanto, a sessão de fotos para o catálogo foi realizada no litoral do Taiti. Mesmo com tal contradição, é notável a influência da modelagem do beachwear brasileiro na coleção estrangeira.

Segundo Sousa; Neira e Bastian (2010), parte disto é atribuído à mobilização arquitetada, desde 2003, pela Associação Brasileira de Estilistas (ABEST), em conjunto com Agência Brasileira de Promoção de Exportações e Investimentos, a Apex - Brasil, em prol do desenvolvimento e da internacionalização do setor têxtil e de vestuário nacional. Sousa e Hardagh (2008) enfatizam, ainda, a influência desta mobilização no perfil multifacetado do profissional em formação, voltado para a atuação multidisciplinar:

\footnotetext{
"Além de cumprir as exigências intrínsecas á prática profissional, busca-se acompanhar a internacionalização do mercado, pela multiplicação de ofertas de formação específicas, voltadas para os diversos subcampos de toda a cadeia têxtil e de vestuário. Esta opção, aliás, se reflete na ampliação do perfil da formação em moda oferecida no Brasil: um profissional que atua no varejo e na produção, assim como na gestão de negócios e marketing." (SOUSA E HARDAGH, 2008, p. 6)
}

Positivamente, para se enfrentar o desafio mencionado por Rucki, de consolidar uma moda efetivamente inovadora e autêntica, a perspectiva de investimento na formação profissional e acadêmica obteve relativo destaque no contexto nacional. 
Silva, Barbará Cravo da; Nascimento, Luis Cláudio Portugal

Em 1998, segundo Pires (2002), durante o "10 Encontro Nacional de Coordenadores e Dirigentes de Cursos Superiores e Representantes de Classe de Estilismo de Moda do Brasil", realizado em Fortaleza, foi deliberado que o programa curricular dos cursos da Faculdade Santa Marcelina e Universidade Anhembi Morumbi estavam aptos a nortear, na condição de elemento de consulta, a definição da Proposta de Diretrizes Curriculares dos Cursos Superiores de Moda, por estarem em consonância com as necessidades e realidade da moda brasileira do período em questão.

No momento atual, a partir do recente diálogo com o design, é proposta a renovação dessa base de consulta, realocando-a nas diretrizes curriculares dos cursos superiores em design. Grande parte dos cursos originados nos anos 1980, juntamente com os demais que foram surgindo até hoje, estão em processo de adaptação à transição de nomenclatura para o Design de Moda, que envolve, entre outras mudanças, a reestruturação de componentes curriculares e inclusão de disciplinas com foco em design, como "Metodologia de Projeto" e "Fundamentos de Design". Ao que Sousa; Neira e Bastian (2010) acrescentam:

\footnotetext{
"Tais diretrizes têm permeado a cultura de ensino de moda no Brasil: conhecimentos e práticas do campo do design passaram a conviver com os mais tradicionais do campo da moda e a própria cultura do design também começou a se aproximar mais daquela, tratando mais profundamente de aspectos socioculturais e simbólicos, entre outros." (SOUSA; NEIRA; BASTIAN, 2010, p. 1)
}

Neste contexto, o diálogo estabelecido entre design e moda objetiva minimizar a centralização do processo de desenvolvimento do produto de moda na figura de um único criador, bem como, o estereótipo da inspiração sem fundamentação como gestora do processo.

Dentre os estudantes que optam por cursos na área de moda, muitos carregam consigo o entendimento de que o processo de desenvolvimento da moda é centralizado na inspiração que aflora repentinamente, sem envolver técnica ou reflexão - pensamento este estimulado pela mídia em torno dos estilistas e desfiles. Quando ingressam no ensino superior e tem contato com as práticas e exigências do ambiente acadêmico, deparam-se, segundo RECH (2002, apud MONTEMEZZO, 2003), com a deficiência de bibliografia direcionada à moda que estimule discussões para além dos temas abordados em cadernos de tendência ou biografias de estilistas famosos. Lipovetsky (2009) argumenta que a ideia do profissional que necessita apenas de talento pessoal é associada à imagem do costureiro criador desde Charles Frederick Worth e a imposição de que sua atividade consiste em "elaborar modelos inéditos, em lançar regularmente novas linhas de vestuário que, idealmente, são reveladoras de um talento singular, reconhecível, incomparável." (LIPOVETSKY, 2009, p. 91).

Deste modo, é possível visualizar que a relevância da transição não reside apenas no âmbito terminológico ou curricular, mas na manifestação de que o entendimento sobre o desenvolvimento do produto de moda também foi alterado, o que Montemezzo (2003) evidencia:

\footnotetext{
"Mesmo que em muitas [instituições de ensino] a mudança do enfoque da atividade se restrinja à mera mudança de nomenclatura, ou mesmo que esta tenha sido adotada por tendência de moda, é evidente que o ponto de vista sobre os produtos de vestuário mudou e, por conseguinte, os aspectos sociais, ergonômicos, ambientais e mercadológicos que o envolvem passaram a fazer parte das preocupações do seu desenvolvimento." (MONTEMEZZO, 2003, p. 52)
}

A contribuição do campo do design para o desenvolvimento de produto de moda pode ser percebida, principalmente, na quebra de paradigma proporcionada pela transição do pensamento de concepção como algo envolto em uma bruma mística, para a configuração pautada em pesquisa e fundamentada em procedimentos e metodologias.

Com base nas informações apresentadas, pode-se visualizar dois pontos críticos e pouco discutidos sobre a implementação do design de moda na academia, ocasionados tanto pelo caráter recente do tema, quanto pela superficialidade de contato e articulação de conteúdos entre os campos: de um lado, a não adequação de fato do projeto pedagógico do curso de moda às diretrizes do design, 
Apontamentos acerca da integração entre conteúdos de design e de moda no percurso ... design de moda

aderindo ao novo modelo proposto sem se aprofundar em seus conceitos e implicações; de outro, a contestação da própria implementação do design de moda por certos grupos internos ao campo da moda.

\section{A interação entre conteúdos de design e de moda}

O presente momento de implementação e legitimação do design de moda no âmbito acadêmico só é possível pela visão crítica das pesquisas em moda sobre o processo criativo e produtivo da moda que, à luz dos conceitos do design e outros campos, frequentemente é associada "a um mundo superficial, reino do transitório, do efêmero, e é entendido poucas vezes como uma prática projetual de profundo impacto na cultura e na sociedade." (FIORINI, 2008, p 95).

No entanto, a existência do design de moda não submete, obrigatoriamente, todo o campo de moda às diretrizes do design. $O$ cerne da proposta de reestruturação do processo de desenvolvimento de produto de moda é a transição da criação artística para o pensamento projetual pautado no processo de design. E, a partir deste, gerar reflexões críticas para o aprimoramento da atividade, de modo a permitir a equiparação de conteúdos entre os campos e a revisão de opiniões superficiais tanto da moda sobre o design, quanto do design sobre a moda.

Para minimizar interpretações errôneas a respeito da moda, faz-se necessário um esclarecimento sobre a abrangência do termo, que perpassa sua interpretação como "fenômeno social da mudança cíclica dos costumes e dos hábitos, das escolhas e dos gostos, coletivamente validado e tornado quase obrigatório." (CALANCA, 2008, p. 11), mas que não se limita a esta possibilidade. A moda presenciada hoje, extremamente cíclica e efêmera, é um forte indicativo da sociedade em que ela está inserida, uma vez que pode também ser entendida como "produto do contexto particular de cada época e de um lugar determinado" (FIORINI, 2008, p 103). Sendo necessário estabelecer visões distintas sobre o fenômeno social moda e o campo do conhecimento moda.

O campo do design tem de compreender a complexidade social e cultural que a moda engendra para, então, pensar a articulação do conteúdo projetual. Assim como a moda tem de se munir conceitualmente para a assimilação do conteúdo de design.

Como anteriormente mencionado, muitas instituições e profissionais estão adotando a transição de forma passiva, sem crítica ou reflexão a respeito da alteração de condutas necessária para sua execução de fato.

A respeito disto, Fiorini (2008) expõe a falta de aprofundamento metodológico na área de moda perante as especificidades da implementação do design de moda e suas implicações e exigências. Aponta, ainda, duas questões a serem consideradas, que vão além da terminologia e se encontram pouco exploradas:

\footnotetext{
"Como pensar a metodologia projetual como eixo transversal aplicável a todos os campos do desenho [design], ou seja, os aspectos gerais e os pontos em comum com outras disciplinas projetuais?

Definir qual seria o aporte próprio da disciplina do desenho da indumentária. Quais são as particularidades que definem o objeto de estudo, que apresenta outras instâncias de reflexão ou outros aportes metodológicos?" (FIORINI, 2008, p. 97)
}

A partir desta visão, o design de moda tem um importante percurso de equiparação de conteúdos a percorrer para atingir sua legitimação.

Montemezzo (2003) busca demonstrar a relevância dos princípios projetuais do design para a estruturação do processo de criação em moda e, por conseguinte, para o processo de desenvolvimento de produto do design de moda, com a finalidade de contribuir para a construção de conhecimento em torno da discussão e resolução dos questionamentos acima citados.

A pesquisa desenvolvida por Montemezzo (2003), apresentada em sua dissertação de mestrado, situa-se no período referente à discussão da transição da moda para o design de moda, tendo como objetivo "verificar, entre estudantes de moda, a ocorrência de mudanças na organização do pensamento relativo ao processo de criação de produtos de moda, após o contato com princípios 
Silva, Barbará Cravo da; Nascimento, Luis Cláudio Portugal

de design" (MONTEMEZZO, 2003, p. 67), coletando importantes dados que indicam o aprimoramento do raciocínio projetual do aluno por meio de conteúdos do design aplicados aos processos de moda. A autora parte da avaliação da proposta de Rech (2002), sendo aqui entendido e posicionado num momento anterior à transição, situando-se no período em que a moda está à procura de fundamentação teórica e metodológica, porém ainda não vinculada intrinsecamente ao design.

Neste contexto, pode-se afirmar que Montemezzo (2003) complementa Rech (2002) ao detectar similaridades entre a estrutura de sua proposição e a metodologia projetual do design. Então, fundamentada nas etapas do processo de design de produto delimitadas por Lobach (2001), sugere um aprimoramento das fases do projeto de moda, propondo etapas projetuais do desenvolvimento de produto de moda com foco em design. Como já mencionado, o momento de tal proposição é de transição, sendo talvez precipitado defini-las como etapas projetuais do design de moda, o que é evidenciado no título da dissertação: "Diretrizes metodológicas para o projeto de produtos de moda no âmbito acadêmico", apontando direcionamentos muito coerentes com o futuro que a transição moda/design de moda apontava e demandava.

Figura 1: Síntese das propostas de Rech(2002), Lobach (2001) e Montemezzo (2003).

\begin{tabular}{|c|c|c|}
\hline $\begin{array}{l}\text { Rech } \\
(2002)\end{array}$ & $\begin{array}{l}\text { Löbach } \\
\text { (2001) }\end{array}$ & $\underset{(2003)}{\text { Montemezzo }}$ \\
\hline $\begin{array}{c}\text { Desenvolvimento } \\
\text { produtos/moda }\end{array}$ & $\begin{array}{c}\text { Processo de design } \\
\text { de produto }\end{array}$ & Fases do projeto \\
\hline $\begin{array}{c}\text { Geração } \\
\text { do conceito }\end{array}$ & Preparação & Preparação \\
\hline Triagem & Geração & Geração \\
\hline Projeto preliminar & & Avaliação \\
\hline $\begin{array}{c}\text { Avaliação } \\
\text { melhoramento }\end{array}$ & Avaliação & Concretização \\
\hline $\begin{array}{l}\text { Prototipagem } \\
\text { projeto final }\end{array}$ & Realização & $\begin{array}{l}\text { Documentação } \\
\text { para produção }\end{array}$ \\
\hline
\end{tabular}

Fonte: própria a partir de Montemezzo (2003).

Montemezzo (2003) evidencia, ainda, a contribuição do enfoque projetual no desenvolvimento de produtos de moda ao apresentar os resultados de sua pesquisa aplicada no curso de Estilismo em Moda da Universidade Estadual de Londrina (UEL) no Paraná. Enfatiza a incorporação ao repertório dos alunos, após terem contato com as disciplinas e conteúdos de design, de palavras como "problemática" e a noção de integração de etapas, tendo propagações no modo de compreender o projetar, levando ao que a autora destaca como elementos essenciais da formação acadêmica:

“a) a focalização do projeto no usuário/consumidor; b) a decodificação tendências de moda e comportamento; c) a síntese dos valores estético-simbólicos associados aos valores práticos; d) a transposição do conceito para a materialização do produto; e) a visão panorâmica do processo." (MONTEMEZZO, 2003, p. 63)

Este percurso abre importante espaço para discutir os limites e possibilidades do desenvolvimento de produto de moda brasileiro e a formação dos profissionais que devem transpor tais conteúdos às empresas do setor têxtil e de vestuário.

Em relação à discussão de integração dos conteúdos de moda e design, Pitombo (2010) visualiza o que pode-se denominar dicotomia inerente ao design de moda, distinguindo duas vertentes 
antagônicas; de um lado, design e, de outro, estilo:

\begin{abstract}
“(...) por um lado aqueles que defendem o design e a moda inserida e reconhecida enquanto fenômeno inscrito numa ambiência que requer o reconhecimento da necessidade de planejamento ou como defendem alguns, de uma abordagem sistêmica atenta às demandas do mercado; e por outro, aqueles que continuam apostando no estilo e concebendo a dinâmica da criação da moda, como algo que se encontra ancorado no horizonte da arte ou do processo artístico." (PITOMBO, 2010, p. 123)
\end{abstract}

Dando sequência a sua argumentação, Pitombo (2010), apoiada em Pareyson (1993), sugere o conceito de formatividade como possível reparador desta dicotomia, de modo a conjugar elementos de funcionalidade e artisticidade:

\begin{abstract}
"Neste sentido, acredito que uma maneira interessante de tentar responder aos desafios do designer de moda é adotar a perspectiva de Luigi Pareyson (1993) que reconhece a arte como uma atividade formativa. Dizer, pois, com Pareyson, que a arte é formatividade, é reconhecer que ela é invenção, sim, mas um tipo de inventividade que floresce no próprio ato de execução, no contato com a matériaprima. O artista produz, assim, concomitantemente, a obra e o seu próprio modo de produzir, ou seja, o seu estilo." (Pitombo, 2010, p. 126),
\end{abstract}

Contudo, a abordagem proposta por Pitombo (2010), sob a perspectiva da formatividade, é centrada em processos e discussões que permeiam o campo da arte, sendo assim, estabelece relação com a vertente anteriormente citada como estilo, não apreciando, em profundidade, conteúdos de design que estabeleçam relação com conteúdos de moda, estando eles em convergência ou divergência.

Talvez seja este o ponto crucial da mudança pela qual as bases pedagógicas dos cursos vêm passando, a alteração da perspectiva artística sobre o estilista e seu processo criativo, transpondo para a perspectiva do designer de moda como intermediário dos interesses da empresa e do usuário. A dicotomia entre design e estilo é um desafio a ser vencido por meio da pesquisa, com o intuito de promover a integração dos conteúdos.

\title{
Design de moda e seu ambiente de atuação
}

Ao instaurar a vigência do design de moda, exige-se um esforço ainda maior de assimilação e equiparação de conteúdos teóricos dos respectivos campos por meio de revisão bibliográfica, a fim de entender e minimizar lacunas conceituais. Isto para que, por meio dessa assimilação de conteúdos, o design de moda possa introduzir o pensamento de design no cotidiano das empresas, visto que, segundo dados do Centro de Design do Paraná (2006 apud Pires, 2007, p.7), a moda é "o setor que mais copia modelos produzidos nos centros difusores, com adaptações ao clima e oferta de matéria prima".

A moda brasileira, ao incorporar o raciocínio projetual proposto pelo design às etapas de pesquisa anteriores ao projeto e que delimitam sua atuação, como pesquisa de público, mercado e tendências, estabelece um ponto de abertura para a discussão de novas problemáticas para a moda, indo além de sua capacidade de incitar o consumo, como evidencia Fiorini (2008):

“(...) o projeto de desenho apresenta-se como um processo de pensamento, cuja gênese está fundamentalmente em uma análise crítica dos condicionantes do problema e cujo fim será uma resposta integradora desse caminho percorrido, (...) deve abranger todas as situações que afetaram a vestimenta: o ambiente, a relação com outros objetos e artefatos culturais, as funções que ela deve cumprir, sua relação com outros sistemas significativos, suas características formais e técnicoprodutivas." (FIORINI, 2008, p. 97)

Em consonância ao que Sousa e Hardagh (2008) referenciam como desenvolvimento da 
capacidade de problematização proporcionado pela abordagem projetual do design. Ao que Bonsiepe (2011, p. 229) complementa: "assim, deve-se considerar que a atividade projetual leva à formulação de novas perguntas cujas respostas dependem de novos conhecimentos gerados pela pesquisa". A resolução do problema não reside no produto, mas sim na problematização acerca dos dados coletados nas pesquisas sobre o usuário e seu universo.

Neste sentido, Almeida e Wajnman (2005) apresentam importante parecer sobre as diferentes vertentes de estudo da moda ao evidenciar a distinção entre dois grandes polos de produção do conhecimento: de um lado, os temas que circundam a cadeia produtiva e distributiva do vestuário e, de outro, a moda enquanto fenômeno social e objeto de pesquisa:

\begin{abstract}
“(...) Um deles é constituído pelos estudos aplicados que visam aprimorar o gerenciamento da cadeia produtiva e distributiva do vestuário de moda (incluindo desde a fabricação de fios até a produção de desfiles de moda) e estão voltados, em última instância, para a produção e reprodução de capitais neste setor econômico e, portanto, às formas de exercícios de poder que garantem este processo.

O outro é conformado pelas pesquisas que tomam a moda como fenômeno relevante para a compreensão de problemas relacionados à estrutura social, motivações psicológicas, comunicação não verbal etc, cujo objetivo é a elaboração de uma abordagem crítica do fenômeno que desenvolva com rigor conceitos, metodologias e teorias que inovem sua compreensão e permitam o questionamento das práticas sociais que se estabelecem e se reproduzem em torno dela." (ALMEIDA;WAJNMAN, 2005, p.25)
\end{abstract}

Com foco na delimitação apresentada, pretende-se estabelecer um paralelo com o presente momento de implementação do design de moda no Brasil. Tendo em vista o campo de atuação do design de moda, considera-se que suas articulações não são restritas às práticas produtivas, uma vez que também interage com a produção do conhecimento gerada pela discussão das estruturas e práticas sociais.

Deste modo, propõe-se a interpretação de que o design de moda não está inserido, integralmente, em nenhum dos dois polos mencionados, mas atua como elemento de conexão entre os saberes desenvolvidos por eles.

Figura 2: Ambiente de atuação profissional do design de moda.

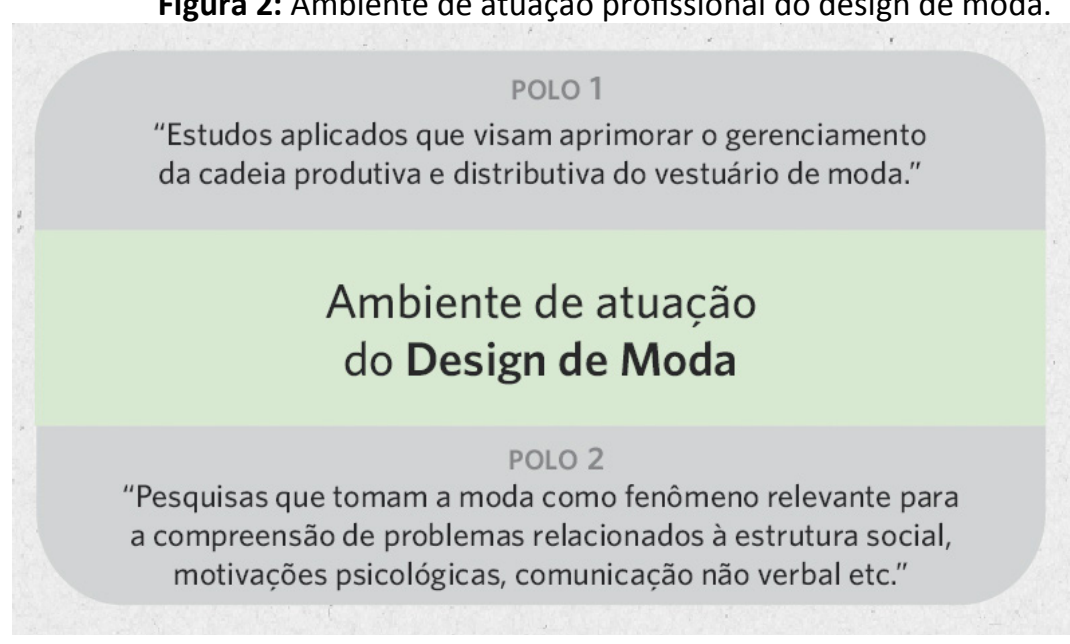

Fonte: própria a partir de Almeida e Wajnman (2005).

O designer de moda, mesmo desenvolvendo seu trabalho no âmbito do primeiro polo, dentro de uma empresa e atrelado a prazos e determinantes administrativos, projeta para indivíduos que utilizarão o vestuário dentro do sistema social discutido e analisado pelo segundo polo, sendo ele o responsável por estabelecer a ponte entre os dois e apontar suas rupturas e possibilidades. Assim como, decodificar e incorporar elementos das duas vertentes, apresentando-os em forma de produto. 
Apontamentos acerca da integração entre conteúdos de design e de moda no percurso ... design de moda

A presente argumentação pauta-se, também, no quadro desenvolvido por Sanches (2011), que demostra a importância do designer visualizar o contexto em que está inserido o projetar, a fim de estabelecer correspondência entre atendimento das necessidades do usuário e estrutura produtiva e gestão da empresa.

Figura 3: Análise do contexto que envolve o projetar. "Fluxo de Informação e Síntese na Fase de

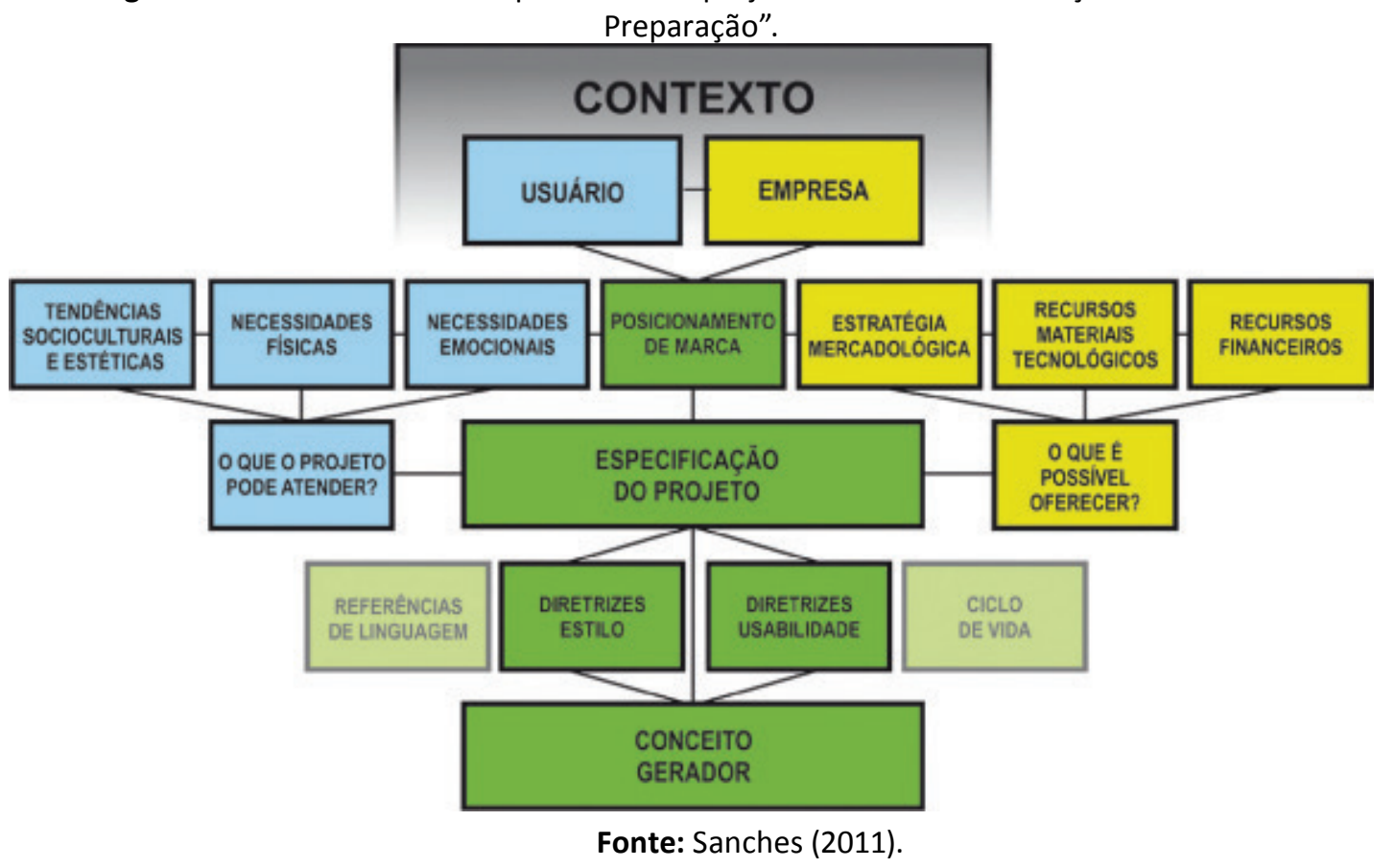

Neste sentido, é possível evidenciar certa relação entre o contexto sugerido por Sanches (2011) e os polos de pesquisa de moda anteriormente analisados na Figura 2, uma vez que as relações e articulações demonstradas no quadro desenvolvido por Sanches (2011), de certa forma transpõe a argumentação apresentada por Almeida e Wajnman (2005) para o ambiente de atuação profissional do design de moda, demonstrando a importância da capacidade problematizadora e visão sistêmica do design de moda tanto no ambiente acadêmico, quanto no profissional.

\section{Considerações Finais}

O surgimento e implementação do design de moda no âmbito acadêmico estabelece um novo patamar de discussão entre os campos da moda e do design. Ao compartilhar este novo segmento, o seguinte questionamento é gerado: até que ponto o design de moda realmente tornou-se homogêneo ou apenas uma justaposição de conceitos?

Embora design e moda tenham origens e percursos históricos distintos, isto não impossibilita elementos de compatibilidade entre seus conceitos, porém, a integração de conteúdos entre os campos, proposta e concretizada no design de moda, passa por seu momento de amadurecimento e se depara, naturalmente, com críticas e pontos de incompatibilidade.

Deste modo, faz-se necessário promover uma maior delimitação e aprofundamento sobre as confluências e dissonâncias entre design e moda, intrínsecas ao design de moda, de modo a contribuir para a integração entre os campos por meio da articulação de conceitos e análise comparativa de percursos históricos. Logo, o design de moda é responsável pela realização desta equiparação de conteúdos entre design e moda, a qual envolve grandes transformações e quebra de paradigmas. 
Silva, Barbará Cravo da; Nascimento, Luis Cláudio Portugal

\section{Notas}

1(Disponível em: http://vogue.globo.com/moda/news/from-brazil-with-love-as-primeiras-fotos-do-catalogo-demoda-praia-da-vs/)

\section{Referências}

ALMEIDA, A. J; WAJNMAN, S. (Orgs.). Moda, comunicação e cultura - Um olhar acadêmico. Editora Arte e Ciência, SP, 2005.

CALANCA, D. História social da moda. São Paulo: Editora SENAC. 2008.

FIORINI, V. Design de moda: abordagens conceituais e metodológicas. In: Pires, D. B. (Org). Design de moda - olhares diversos. Barueri: Estação das Letras e Cores, 2008.

MONTEMEZZO, M. C. F. S. Diretrizes metodológicas para o projeto de produtos de moda no âmbito acadêmico. Bauru, 2003. (Disponível em: www.faac.unesp.br/posgraduacao/design/dissertacoes/ pdf/Maria_Celeste_Montemezzo.pdf)

PIRES, D. B. A história dos cursos de design de moda no Brasil. Revista Nexos: Estudos em Comunicação e Educação. Especial Moda, Ano VI, no 9. São Paulo: Anhembi Morumbi, 2002.

Letras, 2007.

. Design de moda: uma nova cultura. Revista Dobras, n 1, p. 66-73. Barueri: Estação das

PITOMBO, R. Entre design e estilo: a busca pela formatividade. In: Modos de ver a moda. Marques Filho, A. A.; Mendonça, M. C. M. M. (Orgs.). Goiás: Puc Goiás, 2010.

SANCHES, M. Uma análise da delimitação projetual no design de moda. In: Anais VI Ciped, Congresso internacional de pesquisa em design, 2011.

SOUSA, C. S. M.; HARDAGH, C. C. Problematizando o design de moda - O papel da disciplina design de projeto. In: Anais $8^{\circ}$ Congresso de Pesquisa e Desenvolvimento em Design. São Paulo, 2008.

SOUSA, C. S. M.; NEIRA, L. G.; BASTIAN, W. Regulação do ensino do design de moda: Para quem? In: Anais 9o Congresso Brasileiro de Pesquisa e Desenvolvimento em Design. São Paulo, 2010. 